sidered realistically as a problem which is separate from the goals and practices of institutions of higher education, because it is tied to organisations and their aims, and the personalities, policies, goals and criteria of those within them. ..."

In the wider world the problems are the same but the difficulties are even greater. Faced with them, the doctor will often find it much easier to see each individual as a suitable case for treatment-or not-and to regard the institution or the world as an immutable bit of reality to be adjusted to but never questioned. Even with physical medical conditions this is a narrow viewpoint, but when dealing with the social and intellectual performances and experiences of people such an attitude is a dangerous form of tunnel vision. The problems of American students described by Kuehn and Kuehn ${ }^{1}$ raise issues which question both the narrow conceptual framework and the defensive professional isolation in which, as doctors, we are so often content to work.

${ }^{1}$ Kuehn, J K, and Kuehn, J L, American Fournal of Psychiatry, 1975, 132, 1207.

${ }^{2}$ Pervin, L A, Reik, L E, and Dalrymple, W, eds. The College Dropout and Utilisation of Talent. Princeton, NJ, Princeton University Press, 1966.

3 Blaine, G B, and McArthur, C C, Emotional Problems of the Student, 2nd edn. London, Butterworth, 1971.

4 Sexton, V S, Fournal of General Psychology, 1965, 72, 301.

5 University Grants Committee, Enquiry into Student Progress. London, HMSO, 1968.

${ }^{6}$ Kelvin, R P, Lucas, C J, and Ojha, A B, British fournal of Social and Clinical Psychology, 1965, 4, 244.

7 Payne, J, Research into Student Mental Health. London, Society for Research into Higher Education, 1969.

${ }^{8}$ Ryle, A, Student Casualties. Harmsworth, Penguin, 1969.

9 Snyder, B R, The Hidden Curriculum. New York, Knopf, 1971.

${ }^{10}$ Miller, G W, Success, Failure, and Wastage in Higher Education. London, Harrap, 1970.

\section{Vitamin $C$ and the common cold}

The suggestion that ascorbic acid in daily doses of $1 \mathrm{~g}$ or more might be used in the prophylaxis or alleviation of the symptoms of the common cold antedated Linus Pauling's book ${ }^{1}$ but undoubtedly received considerable impetus from his writings. The subject has been reviewed ${ }^{2}$ in the $B M \mathcal{F}$, but new evidence has appeared since then which makes a brief reappraisal appropriate.

A normal diet should contain at least $30 \mathrm{mg}$ of vitamin $\mathrm{C}$ daily, ${ }^{3}$ and this will maintain ascorbic acid concentrations in both the plasma and leucocytes in the normal range in healthy subjects. Nevertheless, leucocyte ascorbic acid (LAA) falls rapidly in the course of the common cold, returning spontaneously to normal as the symptoms resolve around the fifth day ${ }^{4}$ - a response which with a longer time course also occurs in other "stressful" conditions such as after myocardial infarction. ${ }^{5}$ The bactericidal activity of polymorphonuclear leucocytes partly depends on adequate supplies of ascorbate, which stimulates several biochemical processes including the hexose monophosphate shunt-a pathway inhibited in vitro by corticosteroids. ${ }^{6}$ The diminished LAA found in infections may reflect both increased turnover of ascorbic acid and, to some extent, impairment of uptake by the cells themselves. ${ }^{7}$ The fall in LAA at the beginning of a cold has been shown not to be prevented by prophylactic treatment with ascorbic acid ( $1 \mathrm{~g}$ per day) but it can be limited by large doses $(6 \mathrm{~g}$ per day) given from the onset of symptoms. ${ }^{4}$
Whether or not this chain of circumstantial evidence linking adequate tissue defences with supplementary ascorbic acid can be translated to clinical practice depends on the results of clinical trials, but these have proved difficult to design and interpret. A controlled study at the Common Cold Research Unit in $1967^{\circ}$ found no protective benefit from $3 \mathrm{~g}$ of ascorbic acid daily in volunteers inoculated with cold viruses. The first of the two large-scale studies from Toronto ${ }^{9}$ concluded that patients receiving large doses of vitamin $\mathrm{C}$ had significantly less disability from colds and other illnesses than a wellmatched placebo group. Nevertheless, it was impossible to decide whether this was due to the regular prophylaxis or to the therapeutic dose of $4 \mathrm{~g}$ daily taken for the first few days of the illness. A second study lasting 90 days in the winter of 1975 concerned 2349 persons in eight treatment groups. ${ }^{10}$ Tablet counts confirmed a very high compliance with the regimen, but the trial showed only a marginal and probably insignificant benefit of ascorbic acid in prophylaxis and no evidence of a dose-related response. Even so, even in this well-nourished population, large therapeutic doses (4-8 g per day) started at the onset of the illness appeared to reduce the duration and extent of disability from acute infections. The Canadian authors included in their analysis all acute infections and pointed out the difficulty of an accurate diagnosis of the common cold in such a large population. Their results contrasted with those obtained in two studies in schoolchildren ${ }^{11} 12$ in which benefit was claimed from ascorbic acid prophylaxis. Both have been criticised on the grounds of their difficulties in maintaining "blind conditions," in reporting symptoms, and in statistical analysis. ${ }^{13} \mathrm{~A}$ more recent American study of adult employees of the National Institutes of Health reported in 1975 found no significant prophylactic or therapeutic benefit from ascorbic acid. ${ }^{14}$ The same conclusion was also reached in another British double-blind trial against placebo in 295 persons. ${ }^{15}$

What practical recommendations emerge from this new evidence? Major advances in treatment are usually apparent after a few well-conducted studies, and at present no strong evidence can be found to support the routine prophylactic use of ascorbic acid in well-nourished people. Apart from the possibility of long-term side effects, ${ }^{16}$ it is difficult to escape the conclusion that most of the administered vitamin will be lost in the urine within a few hours of eating it once tissues are saturated. Uncertainty continues about a possible reduction of symptoms and disability from therapeutic ascorbic acid, but there is little likelihood of toxicity with large doses over a short period. Perhaps the most valuable outcome of the recent interest in ascorbic acid has been that it has stimulated research into the role of this vitamin in tissue healing and our defence mechanisms against disease.

1 Pauling, L, Vitamin $C$ and the Common Cold. San Francisco, Freeman, 1970.

2 British Medical fournal, 1973, 3, 311.

3 Bartley, W, Krebs, H A, and O'Brien, J R P, Vitamin C Requirements of Human Adults. Medical Research Council Special Report Series No 280. London, HMSO, 1953.

${ }^{4}$ Hume, R, and Weyers, E, Scottish Medical Fournal, 1973, 18, 3.

${ }^{5}$ Hume, R, et al, British Heart fournal, 1972, 34, 238.

6 Cooper, M R, DeChatelet, L R, and McCall, C E, Proceedings of the Society for Experimental Biology and Medicine, 1972, 141, 986.

${ }^{7}$ Wilson, C W M, and Loh, H S, Lancet, 1973, 1, 638.

8 Walker, G H, Bynoe, M L, and Tyrrell, D A J, British Medical fournal, $1967,1,603$.

9 Anderson, T W, Reid, D B W, and Beaton, G H, Canadian Medical Association fournal, 1972, 107, 503.

10 Anderson, T W, Suranyi, G, and Beaton, G H, Canadian Medical Association fournal, 1974, 111, 31.

11 Coulehan, J L, et al, New England fournal of Medicine, 1974, 290, 6.

12 Wilson, C W M, Loh, H S, and Foster, F G, European fournal of Clinical Pharmacology, 1973, 6, 26. 
${ }^{13}$ Dykes, M H M, and Meier, P, fournal of the American Medical Association, 1975, 231, 1073.

${ }^{14}$ Karlowski, T R, et al, fournal of the American Medical Association, 1975, 231, 1038 .

15 Carson, M, et al, British Medical fournal, 1974, 1, 577.

${ }^{16}$ Briggs, M H, Medical fournal of Australia, 1974, 1, 722.

\section{Tubal pregnancy and surgery}

Extrauterine pregnancy, which is almost always tubal, is an increasing contemporary problem. The incidence has risen, ${ }^{1}$ as has the proportion of pregnancies ectopically implanted, more so since 1970. If pregnancy occurs while an intrauterine contraceptive device is in situ the chance that it will be ectopic is greatly increased, ${ }^{2}$ up to nearly 1 in 10 - since, however these devices act, they operate locally in the uterine cavity and exert little or no influence within the tubes. Other possible contributory factors are pelvic inflammation (which has been occurring with increased frequency ${ }^{3}$ ), progestogen-only contraceptives, induced abortion, and tubal surgery including sterilisation. Ectopic pregnancy's proportionate contribution to maternal mortality in Britain has recently more than doubled. ${ }^{14}$ Half the deaths occurred at home or en route to hospital, so clearly prevention is needed as well as early diagnosis and efficient surgical management.

The prime role of surgery for tubal pregnancy is lifesaving; but the procedure performed also affects the woman's future fertility and her risk of a further ectopic gestation. Ectopic pregnancy is apt to be followed by impaired fertility, and recurrence is frequent. Estimates ${ }^{5}$ of the occurrence of impaired fertility range from 33 to $60 \%$. Recently, in a report of 1330 ectopic pregnancies, about one-quarter of the patients were nulliparous, and for this substantial group future fertility prospects are of special importance. In the same series 123 $(9 \%)$ patients experienced repeat tubal pregnancies. ${ }^{6}$

Once surgical treatment for ectopic pregnancy was introduced a century ago ablation of the affected tube became the usual practice. At first the ovary was removed along with the tube; but later, on the grounds that it was usually not affected by the disorder, ovarian conservation became routine and the tube alone was removed. Sometimes the affected tube may also be preserved; this approach was readvocated by Hallatt, ${ }^{6}$ who estimated that $90 \%$ of tubal pregnancies are in the outer two-thirds of the tube, where it is usually possible to perform a conservative procedure.

It is difficult to know how profitable such operations are in terms of subsequent child-bearing and how they influence the chance of a further ectopic pregnancy. In one series of 352 patients with ectopic pregnancies on whom tubal preservation procedures had been performed 119 achieved subsequent intrauterine pregnancy, while 21 had repeat ectopics. ${ }^{6}$ Data such as these, however, do not enlighten us whether the prospects would have been better or worse if the affected tube had been removed.

The prognosis is quite different if the contralateral tube has already been removed or hopelessly damaged. In the series referred to 27 women had conservative operations at the time of second tubal pregnancies, and of these only three were known to have been successful in having a child subsequently, while two abortions and three further ectopic pregnancies also occurred. Though the alternative in these cases was total sterility, these results suggest that the prospects of normal function are poor for a tube which has been reconstituted after bearing an ectopic pregnancy.

An entirely different approach to subsequent fertility was propounded by Jeffcoate 20 years ago. ${ }^{7} \mathrm{He}$ suggested removing the ovary along with the affected tube if the opposite ovary seemed healthy-on the grounds that ova released from the ipsilateral ovary are more likely to become fertilised than those from the contralateral ovary. This is rational if account is taken of the active role of the tube in "fielding" the released ovum from the rupturing follicle. Lawson Tait ${ }^{8}$ described this graphically as "the embracement of the ovary by the Fallopian tube, this embracement being secured by some mysterious and intelligent action of the infundibulum," now attributed to chemotactic influences. This role must be greatly facilitated when the ovary bearing the follicle is on the same side as the tube. No doubt pregnancies may occur after transperitoneal migration of the ovum, but the prospect of fertilisation is reduced: about one in every five ectopic pregnancies is said to have a corpus luteum on the opposite ovary, ${ }^{6}$ implying transperitoneal migration. This figure probably overestimates the chances of fertilisation, as the very occurrence of transperitoneal migration may increase the risk of a tubal implantation, in itself another argument for salpingooophorectomy. Even accepting the one in five figure and given that each ovary contributes an equal number of ova, removal of the ovary along with the tube should result in a $60 \%$ higher fertility prospect.

Statistical support for the suggestion has been slow to appear. One report on 277 women recorded a $45 \%$ conception rate after salpingectomy as opposed to $40 \%$ after salpingo-oophorectomy, but there was a $16.7 \%$ as opposed to $5.7 \%$ incidence of recurrent ectopic gestation in the respective groups. ${ }^{5}$ The philosophy of approach is relevant also to the surgical treatment of infertility, and its application has been reported. ${ }^{910}$ Ten patients with unilateral hydrosalpinx were treated by salpingectomy and ipsilateral oophorectomy, as opposed to 13 who had the ovary conserved. There were five pregnancies in the first group and two in the second. ${ }^{10}$ These numbers are too small for statistical evaluation, but a report at $\mathrm{p} 631$ describes the results of unilateral oophorectomy performed in cases of infertility with unilateral tubal blockage. A statistical technique which compared the incidence of pregnancies in the total period of exposure, before and after surgery, with the incidence in the postoperative phase, showed a significant benefit from the operation. The design of the statistical method was such that a large increase in infertility was required to show significance and, furthermore, many of the pregnancies in this series occurred within a relatively short time of surgery, increasing the probability that the surgery exercised an influence.

Many patients with ectopic pregnancy come to laparotomy without a precise diagnosis (often the diagnostic label is "acute abdomen" or "intraperitoneal haemorrhage"), and the operator may be a general surgeon not accustomed to thinking in terms of the individual's subsequent fertility. Furthermore, even if this is in the surgeon's mind at operation, his decisions are unlikely to be good ones if he does not know the patient's own wishes. Before every laparotomy for suspected ectopic pregnancy, therefore, the patient should be asked about her wishes for future fertility. Frequently, particularly in parous patients, the ectopic will be a consequence of failed contraception; if it is certain that the woman and her husband want no more pregnancies then a sterilising procedure may be wise-not only to save a further operation for sterilisation but 